\title{
Comunicação
}

\section{Comparação entre dois penetrômetros na avaliação da resistência mecânica do solo à penetração}

\author{
Renato Paiva de Lima ${ }^{1}$, Maurício Javier De León ${ }^{2}$, Anderson Rodrigo da Silva ${ }^{3}$
}

\section{RESUMO}

O penetrômetro é o instrumento usualmente indicado para avaliação da resistência mecânica do solo à penetração (RMP). O objetivo deste trabalho foi comparar o desempenho de dois penetrômetros: um eletrônico e outro de impacto, na avaliação da RMP. O trabalho foi realizado na Fazenda Experimental Chã-de-Jardim, Centro de Ciências Agrárias, da Universidade Federal da Paraíba (CCA/UFPB), Areia-PB, em área de Latossolo Amarelo de dimensão $35 \times 35$ m. Os penetrômetros utilizados foram: um de impacto, modelo IAA/Planalsucar-Stolf, e um digital, Falker, modelo PenetroLOG - PLG 1020, com aptidão eletrônica para aquisição de dados em quatro profundidades. Dentro da área, 40 pontos foram amostrados, seguindo duas direções: Norte, para o penetrômetro eletrônico, e Sul, para o de impacto, com os pontos de coleta de cada penetrômetro espaçados em $0,1 \mathrm{~m}$. Os dados foram analisados segundo o modelo de análise de variância de um experimento em delineamento inteiramente casualizado. Os penetrômetros de impacto e Falker apresentaram médias de 1,75 MPa, sendo, portanto, semelhantes na avaliação da RMP em todas as profundidades analisadas, sugerindo que ambos modelos testados podem ser utilizados para solos com características texturais semelhantes as do solo deste estudo.

Palavra-chave: mecânica do solo, física do solo, penetrometria.

\section{ABSTRACT}

\section{Comparison between two penetrometers in the evaluation of soil resistance to penetration}

The penetrometer is an instrument usually suitable for evaluating the penetration resistance of soil (PR). This study aimed to compare the performance of an electronic penetrometer and an impact penetrometer on the evaluation of the PR. The experiment was carried out at the experimental farm Chã-de-Jardim, CCA/UFPB, Areia - PB, in an area of Yellow Latossoil measuring $35 \times 35 \mathrm{~m}$. The impact penetrometer evaluated was an IAA/Planalsucar-Stolf and the digital penetrometer Falker PenetroLOG - PLG 1020, with electronic capability for data acquisition in 4 depths. Within the area, 40 points were sampled following two directions, North for the electronic penetrometer and South for the impact penetrometer, with the sample points of each penetrometer spaced $0.1 \mathrm{~m}$ apart. Data were analyzed following the analysis of variance of a completely randomized design. Both penetrometers showed means of $1.75 \mathrm{MPa}$, being similar on the evaluation of PR for all analyzed depths, suggesting that both devices can be used for soils with textural characteristics similar to those of this study.

Key words: soil mechanic, soil physics, penetrometer.

\footnotetext{
Recebido para publicação em 05/03/2012 e aprovado em 02/04/2013.

${ }^{1}$ Engenheiro-Agrônomo. Departamento de Tecnologia Rural, Universidade Federal Rural de Pernambuco, Rua Dom Manoel de Medeiros, s/n, Dois Irmãos, 52171-900, Recife, Pernambuco, Brasil. renato_agro_@ hotmail.com (autor correspondente).

${ }_{2}^{2}$ Engenheiro-Agrônomo, Doutor. Departamento de Solos e Engenharia Rural, Universidade Federal da Paraíba, Rodovia BR 079, Km 12, 58397-000, Areia, Paraíba, Brasil. mauricio@cca.ufpb.br

${ }^{3}$ Engenheiro-Agrônomo, Mestre. Departamento de Estatística, Universidade Federal de Viçosa, Campus Viçosa, Avenida Peter Henry Rolfs, s/n, 36570-000, Viçosa, Minas Gerais, Brasil. anderson.agro@hotmail.com
} 


\section{INTRODUÇÃO}

A compactação, além de ser um impedimento mecânico ao crescimento radicular, afeta os processos de aeração, condutividade do ar, da água e do calor, infiltração e redistribuição da água, além dos processos químicos e biológicos (Camargo \& Alleoni, 1997; Roque et al. 2003).

A sondagem do solo para a determinação do estado de compactação é um procedimento imprescindível na análise de sua qualidade física, pois a partir deste indicador mecânico avalia-se a necessidade ou não da subsolagem. Silva et al. (2004) afirmam que uma forma de otimizar a operação de subsolagem é realizá-la apenas nos locais e profundidades necessárias para a ruptura das camadas compactadas do solo e que isso pode ser feito dispondo-se de estudos que identifiquem a variabilidade espacial das camadas compactadas do solo a ser mobilizado, em função da resistência mecânica à penetração considerada crítica. A determinação da compactação é fundamental em estudos científicos que avaliam a relação máquina-solo-planta e também contribui para os estudos pedológicos.

Para verificar a existência de camadas compactadas, $o$ penetrômetro é o instrumento que, por meio da resistência do solo à penetração, descreve a resistência física que o solo oferece a algo que tente se mover através dele, como uma raiz em crescimento ou uma ferramenta de cultivo (Pedrotti et al., 2001). Na prática, o conhecimento da resistência à penetração é de extrema importância, pois permite identificar as condições nas quais poderá ocorrer impedimento ao crescimento radicular das plantas.

Os penetrômetros rotineiramente utilizados para a avaliação da compactação são denominados em função do princípio de penetração, podendo ser estáticos, em que o conjunto é pressionado contra o solo, e a resistência à penetração é registrada em um dinamômetro, ou dinâmicos, em que a haste penetra no solo em decorrência do impacto de um peso que cai em queda livre de uma altura constante (Stolf, 1991).

O penetrômetro de impacto tem sido amplamente utilizado no campo para caracterizar a compactação provocada pelo uso e manejo do solo (Tormena \& Roloff, 1996), em razão do baixo custo, da não necessidade de calibração frequente e do fato de os resultados não dependerem do operador. Herrick \& Jones (2002) verificaram que o penetrômetro de impacto é apropriado para todas as aplicações indicadas para os penetrômetros estáticos manuais e recomendado quando a constância de operação do penetrômetro estático é questionável. Porém, os autores mencionam que penetrômetros estáticos eletrônicos apresentam um método mais padronizado.

Com diversos penetrômetros utilizados para levantamento da resistência mecânica à penetração, é importante que se conheça a proximidade de seus resultados, visando a melhora na interpretação dos dados.

O objetivo deste trabalho foi comparar o comportamento de um penetrômetro eletrônico e o de um outro, de impacto, na avaliação da resistência mecânica à penetração.

\section{MATERIAL E MÉTODOS}

O trabalho foi realizado na Fazenda Experimental Chãde-Jardim, Centro de Ciências Agrárias da Universidade Federal da Paraíba, município de Areia, localizado na Microrregião Geográfica do Brejo Paraibano, sob as coordenadas geográficas $6^{\circ} 58^{\prime} 12^{\prime \prime} \mathrm{Se} 35^{\circ} 42^{\prime} 15^{\prime \prime} \mathrm{W}$. Segundo Köppen, o clima é As', quente e úmido, com chuvas de outono e inverno e precipitações médias anuais de 1.200 a $1.400 \mathrm{~mm}$, sendo que mais de $75 \%$ estão concentradas nos meses de março a agosto; temperatura média anual oscilando entre 22 e $26^{\circ} \mathrm{C}$ e a umidade relativa do ar entre 75 e $87 \%$ (Brasil, 1972).

O ensaio foi conduzido em Latossolo Amarelo, conforme classificação da Embrapa (2006). Aárea experimental em estudo vem sendo utilizada, sob intervalos de cultivos, nos últimos 15 anos e, no momento da amostragem, estava sob pousio após colheita de milho, sendo que, naquele cultivo, o preparo do solo foi realizado com uma aração e uma gradagem.

Para a aquisição dos dados, foi considerado um padrão de amostragem, sendo amostrados 40 pontos casualisados em uma área total de $35 \times 35 \mathrm{~m}$, seguindo duas orientações, Norte (N), para o penetrômetro eletrônico, e Sul (S), para o de impacto, com os pontos de coleta de penetrômetro espaçados em 0,1 m (Figura 1).

Foi avaliada a resistência mecânica à penetração, por meio de dois penetrômetros. O primeiro é um penetrômetro de impacto, modelo IAA/Planalsucar-Stolf, com metodologia para coleta de dados sugerida por Stolf (1991). O segundo é um penetrômetro digital FALKER, modelo PenetroLOG-PLG 1020, com aptidão eletrônica para aquisição de dados. Este penetrômetro foi configurado para

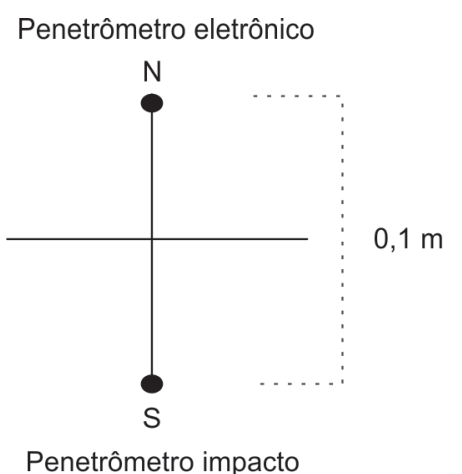

Figura 1. Esquema de aquisição de dados com os penetrômetros na área experimental. 
registrar leituras a cada $0,01 \mathrm{~m}$ de incremento de profundidade, trabalhando em velocidade de penetração constante. Os dados referentes ao penetrômetro Falker foram extraídos da memória digital e analisados a uma profundidade máxima de $0,4 \mathrm{~m}$. Para o processamento dos dados de resistência à penetração, foi utilizado o Software PenetroLOG.

No momento da amostragem, em cada raio envolvendo os 40 pontos coletados foi retirada uma amostra, nas profundidade 0,0-0,2 e 0,2-0,4 m, para análise do teor de umidade e da textura do solo. A análise textural foi realizada no Laboratório de Física do Solo do CCA/UFPB, segundo Embrapa (1997). A umidade foi determinada pelo método padrão da estufa (Embrapa, 1997).

O experimento foi instalado em delineamento inteiramente casualizado, com 40 repetições (pontos amostrais). Foi adotado o esquema de parcelas subdivididas, tendose, nas parcelas, cada um dos pontos amostrais, obtidos com ambos os penetrômetros (Impacto e Falker). Nas subparcelas, as quatro camadas de solo $(0,0-0,1,0,1-0,2$, 0,2-0,3 e 0,3-0,4 m) em estudo. A variável analisada foi a resistência mecânica à penetração $(\mathrm{MPa})$. Os dados foram submetidos à análise de variância e, de acordo com o resultado do teste F, aplicado o teste SNK para comparações múltiplas entre médias.

\section{RESULTADOS E DISCUSSÃO}

Na Tabela 1, são apresentadas as características texturais e a umidade do solo, na área em estudo, no momento da amostragem. Pelas proporções de areia, silte e argila, a classe textural é argilo-arenosa, conforme critérios de Lemos \& Santos (1996).

As percentagens umidades do solo mantiveram-se, em média, com valores próximos nas duas camadas analisadas, sendo de $19,2 \%$ na camada de $0,0-0,2$, e de $20,9 \%$ na profundidade de 0,2-0,4 $\mathrm{m}$.

Na Tabela 2, observa-se a análise de variância dos tratamentos. Verifica-se que não ocorreu efeito significativo para o fator penetrômetro x camadas ( $\mathrm{P}$ x C). Porém, houve diferença significativa para as médias de resistência mecânica à penetração nas diferentes profundidades (Tabela 3).

$\mathrm{Na}$ Tabela 4, observam-se as médias de resistência mecânica à penetração, em $\mathrm{MPa}$, dos dois penetrômetros analisados. $\mathrm{O}$ teste $\mathrm{F}$ não mostrou diferença significativa
( $\mathrm{p}>0,05)$ entre as médias dos penetrômetros, apresentando valores próximos. Estes resultados sugerem que os penetrômetros conduzem a valores relativamente próximos e que podem ser utilizados para solos com características texturais semelhantes (Tabela 1) às do solo deste estudo. Roque et al. (2003) estudaram o comportamento de penetrômetros de impacto e estático e concluíram que apresentam desempenhos semelhantes, na avaliação de diferentes sistemas de uso do solo. Folegatti et al. (1990) compararam os resultados obtidos por um penetrômetro de impacto e um penetrógrafo e concluíram que os dois equipamentos foram eficientes na caracterização da resistência mecânica à penetração, demonstrando a uniformidade na estimativa da resistência mecânica à penetração

Tabela 2. Análise de variância dos resultados obtidos para a resistência mecânica à penetração (RPM) com os dois penetrômetros em diferentes profundidades

\begin{tabular}{lccc}
\hline FV & GL & QM & valor-p \\
\hline Penetrômetro (P) & 1 & 0,0014 & 0,944 \\
Resíduo a & 78 & 0,2816 & - \\
Camada (C) & 3 & 2,7468 & $<0,001$ \\
P x C & 3 & 0,0882 & 0,634 \\
Resíduo b & 234 & 0,1540 & - \\
\hline
\end{tabular}

Média $=1,75$

$\mathrm{CV} \%($ parcelas $)=30,26$

$\mathrm{CV} \%$ (subparcelas) $=22,38$

Tabela 3. Comparação entre médias da resistência mecânica à penetração (RMP) das leituras dos penetrômetros Falker e Impacto em diferentes profundidades

\begin{tabular}{lc}
\hline Camadas (m) & RMP (MPa) \\
\hline $0,0-0,1$ & $1,5041 \mathrm{c}$ \\
$0,1-0,2$ & $1,9413 \mathrm{a}$ \\
$0,2-0,3$ & $1,8267 \mathrm{ab}$ \\
$0,3-0,4$ & $1,7410 \mathrm{~b}$ \\
\hline
\end{tabular}

Médias seguidas de mesma letra na coluna não diferem estatisticamente pelo teste SNK a 5\% de probabilidade.

Tabela 4. Comparação entre médias de resistência mecânica à penetração (RMP), em MPa, dos penetrômetros de Impacto e Falker

\begin{tabular}{lc}
\hline Penetrômetros & RMP $(\mathbf{M P a})$ \\
\hline Impacto & $1,7554 \mathrm{a}$ \\
Falker & $1,7511 \mathrm{a}$ \\
\hline
\end{tabular}

Médias seguidas de mesma letra na coluna não diferem estatisticamente pelo teste $\mathrm{F}$ a $5 \%$ de probabilidade.

Tabela 1. Características texturais do Latossolo Amarelo utilizado no ensaio teor médio de umidade em duas profundidades. Fazenda Experimental Chã-de-Jardim, CCA/UFPB, Areia-PB

\begin{tabular}{lccccc}
\hline \multirow{2}{*}{ Profundidade $(\mathbf{m})$} & Argila & Silte & Areia & & \multicolumn{2}{c}{ Teor de umidade } \\
\cline { 2 - 3 } & & $\mathbf{g ~ k g}^{-1}$ & & & \% \\
\hline $0,0-0,2$ & 386,23 & 77,19 & 536,58 & & 19,2 \\
$0,2-0,4$ & 455,74 & 102,44 & 441,83 & & 20,9 \\
\hline
\end{tabular}


do penetrômetro de impacto, quando comparado com outros equipamentos.

Beutler et al. (2007) compararam três penetrômetros, na avaliação da compactação em Latossolo, verificando que o penetrômetro de impacto apresentou valores superiores de resistência mecânica à penetração, em solos compactados; porém os penetrômetros de anel dinamométrico e eletrônico também foram eficientes na caracterização da compactação. Embora esses penetrômetros apresentem princípios de funcionamento distintos, ambos exercem a mesma função, tornando-se importante conhecer o comportamento desses equipamentos na avaliação da resistência à penetração.

Na Tabela 3, observa-se o teste de média da resistência mecânica à penetração, nas diferentes camadas analisadas. Não houve interação significativa ( $p>0,05)$, mostrando-se os comportamentos semelhantes de ambos os penetrômetros nas diferentes profundidades.

Leite et al. (2010) estudaram os comportamentos de um penetrômetro eletrônico e de um penetrômetro manual em resistência mecânica à penetração conhecida. Os pesquisadores observaram que a resistência do solo à penetração foi maior para o penetrômetro eletrônico, demonstrando a eficácia e a maior sensibilidade do equipamento para detectar a real resistência oferecida.

A variação da RMP entre as camadas do solo é bem conhecida e evidenciada em diversos trabalhos científicos (Carvalho et al., 2008; Teixeira et al., 2003). A pressão de equipamentos mecânicos provoca propagação da força exercida por unidade de área em profundidade, culminando na resposta do solo, na forma de diferentes valores de resistência mecânica ao longo do perfil, sendo esta altamente dependente da carga que é aplicada ao solo (Araújo, 2004).

Roboredo et al. (2010) comentam que o aumento e a variação da densidade do solo e da resistência mecânica à penetração em profundidade, normalmente, estão associados à uma compactação causada pelo manejo e preparo do solo, fato ocorrido na área em estudo, graças aos intensos revolvimentos do solo pelo cultivo do milho. Solos trabalhados sob sistema convencional são intensamente revolvidos, provocando alterações nas propriedades físicas. Estes sistemas utilizam diversas combinações de implementos agrícolas, resultando em camadas compactadas abaixo da profundidade de corte, alterando o comportamento da infiltração e escoamento das águas (Louzada et al, 2007).

Reichert et al. (2009) comentam que as operações agrícolas que envolvem mobilização e tráfego de máquinas alteram a estrutura do solo e modificam as condições que determinam o ambiente de crescimento radicular, provocando variações na resistência mecânica à penetração ao longo do perfil.
Na Tabela 4, verifica-se que a média da resistência mecânica à penetração no solo em estudo é próxima a 1,8 $\mathrm{MPa}$. Assim, ainda que não exista um consenso na literatura sobre valores de resistência mecânica à penetração limitante ao desenvolvimento radicular das plantas, Tormena \& Roloff (1996) comentam que solos que apresentem valores em torno de $2 \mathrm{MPa}$ começam a prejudicar o bom desenvolvimento do sistema radicular, valor, este, que não foi observado nas médias de resistência mecânica à penetração das Tabelas 3 e 4 .

\section{CONCLUSÕES}

Os penetrômetros eletrônico e de impacto mostraramse similares na avaliação da resistência mecânica à penetração, em todas as profundidades analisadas, podendo qualquer um dos instrumentos testados ser utilizado para solos com características texturais semelhantes às do solo deste estudo.

\section{REFERÊNCIAS}

Araújo AG (2004) Estimativa e classificação da compactação do solo pelo tráfego de máquinas agrícolas através da modelagem nebulosa. Tese de Doutorado. Escola Politécnica, Universidade de São Paulo, São Paulo. 224p.

Beutler AN, Centurion JF \& Silva AP (2007) Comparação de penetrômetros na avaliação da compactação de Latossolos. Engenharia Agrícola, 27:146-151.

Brasil (1972) Ministério da Agricultura. Equipe de Pedologia e Fertilidade do Solo. Divisão de Agroecologia - SUDENE. Levantamento exploratório - reconhecimento de solos do Estado da Paraíba. Rio de janeiro, MA/SUDENE. 670p. (Boletim Técnico, 15).

Camargo AO \& Alleoni LRF (1997) Compactação do solo e o desenvolvimento das plantas. Piracicaba, Degaspar. 132p.

Carvalho LA, Neto VJM, Silva LF, Pereira JG, Nunes Waga \& Chaves CHC (2008) Resistência mecânica do solo à penetração (RMP) sob cultivo de cana-de-açúcar, no município de Rio Brilhante-MS. Agrarian, 1:7-22.

Embrapa (1997) Manual de métodos de análises de solo. 2a ed. Rio de Janeiro, Ministério da Agricultura e do Abastecimento. 212p.

Embrapa (2006) Centro Nacional e Pesquisa em Solos. Sistema Brasileiro de Classificação de Solos. Brasilia, Embrapa-SPI. Rio de Janeiro, Embrapa-Solos. 306p.

Folegatti MV, Silva AP \& De Maria IC (1990) Avaliação da resistência do solo utilizando penetrômetro e penetrógrafo. In: XIX Congresso Brasileiro de Engenharia Agrícola, Piracicaba. Anais, SBEA. p.525.

Herrick JE \& Jones TL (2002) A dynamic cone penetrometer for measuring soil penetration resistance. Soil Science Society of America Journal, 66:1320-1324.

Leite F, Santos JEG \& Lanças KP (2010) Comparação da resistência do solo à penetração entre penetrômetro elétrico-eletrônico e penetrógrafo manual. Cultivando o Saber, 3:32-39.

Lemos RC \& Santos RD (1996) Manual de descrição e coleta de solo no campo. $3^{\text {a }}$ ed. Campinas, Sociedade Brasileira de Ciência do Solo. 83 p. 
Louzada RO, Senra AF, Vitorino ACT, Souza CMA \& Mochi Victor D (2007) Resistência à penetração em Latossolo Vermelho sob diferentes sistemas de uso e manejo do solo. Revista Ciências Técnicas Agropecuárias, 16:31-36.

Pedrotti A, Pauletto EA \& Crestana S (2001) Resistência mecânica à penetração de um Planossolo submetido a diferentes sistemas de cultivo. Revista Brasileira de Ciência do Solo, 25:521529

Reichert JM, Kaiser DR, Reinert DJ \& Riquelme UFB (2009) Variação temporal de propriedades físicas do solo e crescimento radicular de feijoeiro em quatro sistemas de manejo. Pesquisa Agropecuária Brasileira, 44:310-319.

Roboredo D, Maia JCSM, Oliveira OJ \& Roque CG (2010) Uso de dois penetrômetros na avaliação da resistência mecânica de um latossolo vermelho distrófico. Engenharia Agrícola, 30:307314
Roque CG, Centurion JF, Alencar GV, Beutler NA, Pereira GT \& Andrioli I (2003) Comparação de dois penetrômetros na avaliação da resistência à penetração de um Latossolo Vermelho sob diferentes usos. Acta Scientiarum Agronomy, 25:53-57.

Silva G, Nelson L, Cappelli NL \& Umezu CK (2004) Métodos probabilístico e determinístico para diagnóstico da necessidade de subsolagem de solos. Engenharia Agrícola, 24:130-141.

Stolf R (1991) Teoria e teste experimental de fórmulas de transformação dos dados de penetrômetro de impacto em resistência do solo. Revista Brasileira de Ciência do Solo, 15:229-35.

Teixeira CFA, Pauletto EA \& Silva JB (2003) Resistência mecânica à penetração de um argissolo amarelo distrófico típico sob diferentes sistemas de produção em plantio direto. Ciência Rural, 33:1165-1167.

Tormena CA \& Roloff G (1996) Dinâmica da resistência à penetração de um solo sob plantio direto. Revista Brasileira de Ciência do Solo, 20:333-39. 